\title{
Orgias midiáticas e morte ao vivo: 0 evento-catástrofe no inconsciente visual coletivo
}

\section{Mediatic orgies and death in live: Disaster-event in collective visual unconscious}

\author{
Bertrand Vidal | Université Paul Valéry - Montpellier 3 \\ Doutor em Sociologia pela Université Paul Valéry - Montpellier 3, França. \\ Pesquisador na Université de Nîmes, França. \\ E-mail: bertrand.vidal@live.fr
}

\section{Resumo}

Este artigo propóe-se a explorar a tectônica das imagens de desastres e o imaginário social das catástrofes e, em particular, nossa relação medialógica com esse tipo de acontecimento. Hoje, em uma sociedade onde a presença e a proliferação das imagens no mundo da vida cotidiana são aspectos característicos do ambiente social contemporâneo, nossa relação com o catastrófico parece se cristalizar em torno de uma contradição: atração/repulsão pelas imagens de desastre.

Palavras-Chave: catástrofe; NTIC; imagem

\section{Abstract}

This article explores the tectonic of the images of disaster and the social imaginary disaster, especially our mediological relationship to the disasters events. Today, in a society where the current presence and proliferation of the image in the world of daily life is one of the characteristic aspects of the contemporary social environment, our relationship to the disasters events crystallizes around a contradiction: attraction/repulsion for the images of disasters.

Keywords: disaster; NTIC; image 
$\mathrm{O}$ analfabeto de amanhã não será aquele que ignora a escrita, mas aquele que ignora as imagens. (László Moholy-Nagy citado por Walter Benjamin, Petite histoire de la photographie, 1931).

Aqueles que, em uma perspectiva crítica, condenam os estudos do imaginário - enquadrando-o, na tradição racionalista, em definiçóes de pretensão, falsidade, ilusão, ou mesmo, reduzindo a capacidade da psique individual e coletiva em produzir imagens, sonhos e mitos, como uma forma de alienação - não podem compreender o pululamento contemporâneo das imagens e, sobretudo, o que elas dizem sobre nosso mundo e nossas maneiras de habitar o fluxo daquilo que Alvin Toffler (1984) nomeou de blip culture, essa cultura feita de uma explosão de imagens que se sobrepóem umas às outras. Como explica o teórico da complexidade, Edgar Morin, a invasão no planeta pelas imagens estandardizadas significa que, apesar da racionalização, a intelectualização crescente e o " desencantamento do mundo", "nós estamos sempre possuídos pelas ideias, pelos mitos, pelos deuses" (MORIN, 2006, p. 18). As telas de nossas TVs, dos computadores e, atualmente, dos smartphones, simplesmente substituíram as cavernas.

As imagens, enquanto "estoque de conhecimento" (Alfred Schütz), “instância de fixação" (Philippe Joron) ou "armazém de imagens" (TOFFLER, 1984), com todos seus suportes midiáticos, contribuem à construção da dinâmica dos imaginários sociais, participando assim, cada vez mais, à compreensão cotidiana do mundo, à construção social da realidade e à constituição de uma memória midiática e audiovisual ao mesmo tempo pessoal e coletiva.

A explosão de imagens e de tecnologias visuais que surgiram no final do século passado provocou uma mudança cultural na vida cotidiana dos indivíduos. Assim, a abundância de cartazes publicitários, de tags, de grafites, de telas conectadas nas cidades e nas metrópoles contemporâneas, além do compartilhamento de imagens, fotos e vídeos amplificado pelas redes sociais, com a interconexáo dos dispositivos comunicacionais e o devir tangível e onipresente da informática, ancora o indivíduo em uma sociedade de imagens (ou de interfaces), submetendo o conjunto de nossos aparelhos perceptivos às representaçóes das tecnologias. Como sugere a geógrafa Gillian Rose (2001), especialista nos estudos da cidade e das culturas visuais, a pós-modernidade não é somente "oculocêntrica", devido à quantidade de imagens que circulam e articulam os conhecimentos, mas, também, porque os indivíduos interagem mais com as experiências visuais, monopolizando nossos cinco sentidos, com preponderância da visão. Aliás, hoje em dia, quando um nativo digital deseja "escutar" música, ele prefere a experiência visual dos canais do Youtube àqueles simplesmente sonorizados como Deezer, Spotify ou Itunes.

Nesse sentido, nossa experiência da realidade se dá através de superfícies bidimensionais (telas de todos os tipos) e transdimensionais (Web), que transpiram e destilam toda a essência do imaginário no cotidiano. E se, quando olhamos uma imagem-choque, objeto deste artigo, como sugere Roland Barthes em "Mitologias", "nós estamos cada vez vez mais despossuídos de nossa faculdade de julgamento" (2010, p. 126), é porque, em definitivo, nós só fazemos a suspensão do julgamento - o que a semiótica aborda como pacto 
de veridicção. Nós nos alçamos a um mecanismo de associações no qual real e imaginário não se encontram mais em uma posição antitética, mas se alimentam um do outro para constituir o universo semântico do vivido. Em outros termos, "a lógica do visível comanda a lógica do vivido" (DEBRAY, 1993, p. 295) e desenha o universo das significaçôes sociais. É assim que, por trás da pletora de elementos visuais que nossa sociedade exibe e implanta cada vez mais, - o que alguns não deixarão de chamar de "uma feira de atrocidades" - se esconde uma iconologia do tempo presente, uma definiçáa mítica (DURAND, 1983, p. 12) na qual a cultura floresce e desabrocha.

Longe de ser esse poder de alienação e de mistificação, a faculdade imaginativa possui, ao contrário, uma verdadeira função noética e cognitiva, um papel preponderante no conhecimento do mundo, permitindo ao homem acessar às seções inteiras da realidade que, sem elas, lhe permaneceria para sempre incompreensível. E agora, na hora da realidade das mídias e da "mediarealização" do mundo, o imaginário é mais real que o real; só o que a imagem mediatizada filtra parece incontestável e decisivo. "O que sabemos de nossa sociedade, sobre o mundo no qual nós vivemos, nós apreendemos pelas mídias", anuncia Niklas Luhmann (2013, p. 7). Aliás, os canais de informação contínua, comumente à busca pela informação exclusiva e do efeito integral do real, sempre tentando adiantar o realismo das redes sociais, não se enganaram, como no caso da parceria entre Citizenside ${ }^{1}$ e BFMTV ${ }^{2}$, atuando sobre dois princípios motores dos nossos tempos: compartilhar as visóes do mundo no ciberespaço e focar no "oculocentrismo" da atualidade, ("Testemunhas BFM: Vocês são testemunhas de um evento, envie-nos as suas fotos ou vídeos e compartilhe suas imagens com a comunidade de internaltas"). A imagem torna-se a condição sine qua non da nossa existência real, uma espécie de prova indiscutível que assume as armadilhas da forma elementar da vida diária na era da hiperesfera (DEBRAY, 2005), isso quer dizer que com a "circulação mundial das imagens" (GERVERAUX, 2007, p.15), essa "câmara de ressonância planetária" da qual não escapamos. $\mathrm{E}$, face a esse bombardeio cotidiano de sinais visuais, face ao realismo da imagem-fluxo, face a esse sufocamento em pequenas doses de quantidades enormes de informações e de imagens, em vez de tentar integrar às rubricas padrão, herdadas das esferas medialógicas atualmente desatualizadas, nós aprendemos bem ou mal a lidar com novas categorias de pensamento, nós aprendemos a fabricar nossos próprios canais de ideias a partir do imaterial, incluindo novas mídias e novas tecnologias no imaginário do cotidiano.

Assim, enquanto sistema de produção de realidade, esse conhecimento/ percepção imagético do mundo se abre, sem nenhuma dúvida, ainda mais com a mistura dos eventos no cotidiano, provocando um estranho fascínio estético pelos desastres e catástrofes quando eles surgem no "convívio" (ORTEGA y GASSSET, 1922, p. 17) ou no "ecúmeno" (BERQUE, 2000, p. 20).

Dos atentados de 11 de setembro de 2001 à multiplicação atual e obscena das imagens catastróficas, importa agora indagar sobre o que esse horror produzido pelas mídias representa e como ele é percebido. É sob essa condição que podemos superar a languidez do poder de sideração estética-cognitiva 
das imagens traumáticas das quais falava Roland Barthes (1975, p. 9) e, assim, alcançar a uma inteligência do complexo, visando a descobrir por trás das visôes do apocalipse, as questôes cuja importância se encontra para além do quadro puramente eventual da catástrofe.

Assim não é intenção deste artigo estudar as catástrofes em si, tentar compreender suas causas, seu desenvolvimento, suas consequências ou suas repercussóes geopolíticas e sanitárias cujos efeitos poderíamos medir a cada dia. Nossa intenção reside mais na questão do modo de funcionamento bastante particular da iconografia da catástrofe, sabendo que, hoje em dia, contrariamente ao que se passou na época dos atentados do World Trade Center em 2001, nós não somos mais dependentes da televisão e dos meios de comunicação de massa quando acontecem os eventos-catástrofe. Atualmente, essa "imagofagia" - essas imagens que vemos mais e mais, metaforicamente de maneira bulímica, seja para compreender seja para integrar o evento extraordinário em sua monstruosidade escalonada - pode ser saciada no Youtube, Pinterest ou mesmo nos vídeos do Instagram, os quais nos oferecem uma multiplicidade de pontos de vista sobre o horror. Os GIFs (Graphics Interchange Format) e os VINEs (serviço de armazenamento de vídeos em formato curto), que são trocados nas redes sociais ou que encontramos nas matérias jornalísticas e fóruns de excelente originalidade, substituem a televisão e seus canais de informação no seu papel catártico - como, por exemplo, os GIFs da onda que submergiu a costa pacífica de Töhoku, em 11 de março de 2011; das explosóes sobre a linha de chegada da 117 a maratona de Boston, em 15 de abril de 2013; e ainda do acidente ferroviário de Santiago de Compostela, em 24 de julho de 2013.

\section{Apokalupsis: o museu imaginário das catástrofes}

Por sua onipresença,(...) as imagens, nossas imagens atuais, tornaram-se substancialmente pornográficas. (Jean Baudrillard, Pornographie de la guerre, 2004).

Se, como observa o sociólogo Fabio La Rocca, "a cada época, a imagem adquire sua própria especificidade dentro de um quadro cultural e de formas de experiências" (2001, p. 95), para quem deseja compreender a tectônica das imagens da catástrofe no inconsciente visual do cotidiano, parece ser primordial considerar que, doravante, a propagaçáo das imagens acontece em larga escala, movida pelo que Paul Valéry chamava a ubiquidade e a "distribuição da Realidade sensível a domicílio" (1960, p. 1285). Elas se tornam, tanto para o homem da rua quanto para o filósofo, não somente um meio servindo a veicular uma mensagem, mas também um medium para apreender o mundo, ou melhor, fazendo referência ao sociólogo alemão Georg Simmel, um medium para apreender o "humor" (2006, p.240) ou a "tonalidade afetiva" (BOLLNOW, 1953) da nossa época. É o que demonstram os estudos recentes sobre o formato de imagens "GIF" liderados pelos pesquisadores do Media Lab do MIT, Travis Rich e Kevin $\mathrm{Hu}^{3}$ : mais do que um formato de expressão artística, mais do que uma técnica de imitação do real ou de representação como tende a significar a etimologia latina imago, as imagens tornam-se uma extensáo tecnológica de 
nossa própria linguagem e de nossas diversas maneiras de comunicar/transmitir o sentido, e, na nossa socialidade contemporânea cada vez mais dominada pelas conversas eletrônicas, elas passam a ocupar crescentemente as palavras e as longas explicaçôes textuais, que passam a ser inadequadas ao design digital.

Considerando então "a travessia do espelho" (consubstancial tanto à entrada na videoesfera (DEBRAY, 1991) quanto à utilização massiva das smart-tecnologias de comunicação, e na qual a imagem reencontra sua presença icônica ${ }^{4}$ ), enquanto ela era a mentira e a "aparência enganosa" do iconoclasta, nós podemos afirmar que a imagem é hoje o real das nossas "civilizaçóes de ocunodulia" (DEBRAY, 1991). Ou seja, como estipula o mediólogo Régis Debray, "nós não estamos mais frente à imagem, mas frente ao visual” (1992, p. 298). Sendo assim, os reflexos do real - o imaginário, ousaríamos dizer como Gilbert Durand (1990) - se tornaram mais reais que o real. É assim que predomina o "prosumerismo" da imagem: ou seja, as smarts-tecnologias e as redes sociais numéricas, com a interconecção mundial dos dados pessoais, doravante, dominam as tecnologias da comunicação e as tecnologias do imaginário (Machado da Silva, 2008), nos permitindo ser tanto espectador quanto ator do novo mundo visual.

O "prosumerismo" da imagem é um termo emprestado do futurólogo norte-americano e teórico da "Terceira Onda”, Alvin Toffler (1984). O "prosumerismo" é uma palavra-chave construída à partir da contração dos termos produtor (producer) e consumidor (consumer). Inspirado do construtivismo social, ele significa que percebemos o mundo e, simultaneamente, criamos o mundo: as Novas Tecnologias da Informação e da Comunicação nos conduziram a sermos - espectador(ator) - do novo mundo visual.

\section{A tectônica das imagens da catástrofe}

Aprofundando este exame da tectônica das imagens da catástrofe, nos parece que, a partir de agora, nós devemos estar atentos à nossa relação com a mediatização de uma catástrofe e, por consequência, à construçáo do evento-catástrofe no "inconsciente visual coletivo" de Walter Benjamin e no corpo social, ou utilizando as palavras de Marshall McLuhan, no corpo "auto-amputado" (2004, p. 63) pelas NTIC.

Neste sentido, aguerrir-se do aspecto nodal das tecnologias do imaginário na percepção/criação imaginal do mundo, do terremoto de Lisboa, evento-catastrófico paradigmático na gênese da ideia de progresso ${ }^{5}$, ao desastre de Fukushima, acontecimento que qualificaremos como o economista Frédéric Lordon de "passional" $(2012)^{6}$ o que mudou objetivamente desta vez é que nós não podemos de nenhum modo medi-lo nem sob o prisma do número de mortos, nem em relação às consequências cognitivas ou filosóficas, nem mesmo na ótica dos diversos sistemas de proteção ou gestão do Mal mais ou menos colocados sob os auspícios da fantasmagoria social, nem mesmo ainda dentro da visão dos sistemas de racionalidades mais ou menos "veladas" (Simmel, 2002, p. 73-74) ou "ilimitadas" (SIMON, 1957, p. 339), mas da maneira mais pragmática que seja, bem ou mal, aos dispositivos de comunicação e as tecnologias do imaginário colocadas ao serviço da transmissáo da informação, permitindo doravante ubiquidade e telepresença. 
Nessa "imensa promoção do imediato" (NORA, 1972, p. 164), relativa sem nenhuma dúvida à capacidade de retransmissão contínua, há a abolição radical das distâncias e isenção da diferença de tempo do relato ao real: o evento e seus rastros se confundem.

Assim, se foi preciso esperar quase um ano antes de ter os primeiros testemunhos e escritos ou ainda as primeiras imagens sobre o terremoto de Lisboa no $1^{\circ}$ de novembro de 1755 , hoje, quando um desastre acontece, ele é vivido, percebido e representado imediatamente sobre toda a superfície do globo - fascinante contração/dissolução do tempo entre o fato, sua midiatização e sua recepção. Fatos midiáticos totais, filmados ao vivo, capturados pelos smartphones; comentados, tuitados e retuitados, paradoxalmente "linkados", mas também gravados, divulgados e redivulgados à repetição até a saturação estética dos lineamentos da produção imagética popular, agora vivemos em tempo real as catástrofes - o tempo real da presença icônica é o tempo hiper-real da procissão do simulacro.

Lembremo-nos, por exemplo, da experiência midiática do tsunami entrando pelas costas japonesas no dia 11 de março de 2011. Hora local (14h:46m:23s): ocorre um sismo de magnitude 9 no alto mar do Japão e o EEW (Earthquake Early Warning) deslancha. Assim, a experiência do terremoto se desdobra com a problemática inerente à proteticidade midiática (ao vivo, graças às próteses técnicas). Durante uma hora e meia ao vivo, alguns milhóes de telespectadores, de seguidores e utilizadores das NTIC, grudados à tela, com medo e apreensão ou ainda com prazer mórbido em relação à auto-destruição (Walter Benjamin), esperam 16h, $15 \mathrm{mim}$ e 00 sec precisos para assistirem a submersão fantasmagórica do Japão, cuja ambiência e estética apocalípticas já haviam sido prefiguradas pelo escritor de ciência-ficção Sakyo Komatsu (2000) algumas dezenas de anos antes: uma onda de 6 a 23 metros de altura (segundo as estimativas) penetra no interior das terras, devastando cerca de $600 \mathrm{~km}$ da costa e fazendo desaparecer do mapa várias cidades, tal como a emblemática prefeitura de Sendaï. Assim, na época do desastre de Lisboa, a onda sísmica antecipava a mensagem da catástrofe, hoje na época das NTIC, a onda midiática antecipa o sismo. É o que demonstram as estatísticas de Google ${ }^{7}$ na solicitação "Tsunami + Japão": alguns minutos antes que a onda atingisse as costas Japonesas, o fluxo de buscas (essencialmente para as imagens e vídeos) já havia chegado ao máximo, como se o espectador e o utilizador das NTIC estivessem à espera do spoil. Também então, podemos pensar, que eles não suportavam mais o suspense inerente à progressáo da onda tal como era difundida nos canais televisivos suas de informação contínua. Progressão sem dúvida muito lenta para o modo de existência e de produção do real das mídias contemporâneas ${ }^{8}$.

Trata-se de um processo que ajuda a aprofundar uma outra diferença, e que náo é das menores. Se, em seu tempo, o tremor de terra de Lisboa ficou marcado por uma aversão ao desastre, hoje, o estilo de nossa época, exprime-se num registro até então inédito: o desejo coletivo da catástrofe (JEUDY, 1990) e do Apocalipse, se traduzindo no imaginário popular por um fenômeno de superconsumo das imagens do desastre e do horror, e de uma fascinação pelas metáforas do nosso próprio fim, nossa destruição ou ainda nossa autodestruição. Efetivamente, não é preciso relembrar o fenômeno do "21 de dezembro 
de 2012: o fim do Mundo" e a efervescência recreativa, dionisíaca em vários aspectos, que esse medo escatológico provocou tanto nos blogs e fóruns de internet, assim como nas mediatecas ${ }^{9}$ : existe, de uma certa maneira, a manifestação de um "sintoma de humanidade que se tornou estrangeira a ela mesma" e que, para reutilizar as palavras de Walter Benjamin, numa relação demente com o mundo, "tira prazer do espetáculo da sua própria destruição" (2003, p. 316), convidando a seu próprio apocalipse.

\section{O maior espetáculo transmídia do mundo}

Como escreveu o romancista de ficção científica James Graham Ballard na novela $O$ maior espetáculo de televisáo do mundo, há uma "importância dada à morte e a destruiçáao" (1987, p. 193) quando se produz um episódio ou uma experiência de mass-media, como foi o caso de Boston no dia 13 de abril 2013, do Japão no dia 11 de março 2011, ou ainda de New York no dia 11 de setembro 2001: é o paradoxo da morte ao vivo. O conjunto de nossos universos simbólicos e de nossas galáxias imaginárias se estressam, aliciando desde entáo nosso corpo prolongado e com ele inflamando nossos órgáos mediáticos com auto-amputaçóes até a turgescência e a orgia multimídia da nossa "carne eletrônica" (SUSCA, 2012).

Quando o cotidiano parece recobrar seu curso normal e que o acontecimento catastrófico termina, "post catastrophae, omne animal triste est" um sentimento próximo à melancolia invade a totalidade do corpo (físico e social) ampliado e da nossa memória audiovisual personificada, impulsionando o indivíduo a divagar nas redes sociais, roçando as extensóes tecnológicas e os prolongamentos do sistema nervoso e sensorial, na perspectiva de inflamar uma última vez as zonas erógenas dos nossos órgãos midiáticos.

Como ilustra o Google Trend, o fluxo de buscas por um acontecimento catastrófico sempre sobrevive, durante um momento, dentro do quadro temporal e espacial do acontecimento no digital shadow. Por vezes, ele continua a ser relançado pelo fantástico social e alimenta o inconsciente coletivo: não é raro que o rumor e a atração/repulsão da imagem do desastre forneçam alguns sobressaltos eróticos, proporcionando os últimos calafrios epidérmicos dos quais a infosphére (FLORIDI, 1999) e o cyberspace gostam de se alimentar.

Fica então uma interrogação: portanto, quando se produz um acontecimento catastrófico, esperado ou não, uma espécie de transe mass-midiático, que excita o imaginário popular e força o indivíduo a procurar saber cada vez mais sobre o desastre, não se trata de voyeurismo, procura-se a imagem mais terrível, na expectativa de encontrar uma espécie de quietude paradoxal nos órgãos e sentidos exorbitados pelo horror, com estas imagens que nos assustam e nos causam repugnância?

"Demônio da perversidade” (POE, 2010), o único traço do gênio do homem ocidental, segundo o escritor Blaise Cendrars (1974) é a "Oposição fundamental entre homo faber e homo destruens". Gosto sutil da tábula rasa, como sugere o sociólogo Henri-Pierre Jeudy (1990) em Le désir de catasthophe, lembrando a criança que quebra o brinquedo que construiu. Schadenfreude (1974, p. 370) como avançava o filósofo Friedrich Nietzsche ou ainda o prazer maligno do destrudo (WEISS, 1957, p. 213) chegando até os nossos prolongamentos tecnológicos e órgãos sensoriais 
ampliados. Como demonstram os diversos Web Analytics (programas de análise e de comparação da frequentação dos sites da internet), quando um acontecimento catastrófico se produz, a libido diminui ao benefício do destrudo. É o que se constata na frequentação de sites como youporn, Xporn ou pornhub.com - figuras contemporâneas da nossa libido numérico - diminuindo significativamente o lucro dos vídeos youtube ou dailymotions ${ }^{\mathbf{1 0}}$, verificando-se também a hipótese sublinhada anteriormente pelos romancistas William Burroughs et James Graham Ballard: "que hoje é possível experimentar uma excitação sexual mais intensa face à experiência do desastre e da imagem do acidente do que face à experiência e à imagem pornográfica" (BALLARD, 2003, p. 11).

\section{Libido Versus Destrudo}

Essa sociedade táo bem regulada por nossos tecnocratas
diplomados, presa entre essas novas porcas e parafusos, não
estaria prestes a morrer de tédio? (Jean-Marie Drot, Le temps des
désillusions ou le retour d'Ulysse Manchot, 1971.)

Parece que por trás deste consumo desenfreado de imagens da catástrofe, coexistem vários fenômenos já estudados com atenção pela disciplina sociológica.

De uma parte, nós podemos dizer que certamente se manifesta aqui a atualização daquilo que o pai da sociologia francesa, Émile Durkheim, nomeava de "ritos piaculares", sendo que a expressão contemporânea poderia ser "neo-ritos" expiatórios da era das nuvens digitais e da interconexão informática dos dados.

Por outro lado, parece-nos pertinente notar que se redesenha o que o fundador da sociologia do imaginário, Gilbert Durand, chamava "a visão monárquica", ou seja, "experimentar uma espécie de recuo diante do dado mundano" (1990, p. 209) para finalmente "(...) olhar do alto, como aristocrata, a luta e o sofrimento dos outros” (p. 209) e, assim, compartilhar as lembranças do Imperador Nero em 64: tranquilamente recostado em sua poltrona, prostrado diante da tela da TV, ou mesmo com o smartphone na palma de sua mão, comendo compulsivamente sua batata frita, o cidadão degusta o martírio da cidade. Sabemos desde o Marquês de Sade e "as prosperidades do vício", que não existe limite ao fascínio que uma imagem pode exercer, seja ela qual for.

Em última análise, parece primordial reconhecer que, através desse tipo de fenômeno, exprime-se "a maneira retorcida da qual o homem é feito", como sugere a famosa máxima do filósofo Emmanuel Kant (1947, pp 60-61). O homem não pode ser definido sem levarmos em conta um aspecto, perverso e vicioso, que pode retornar enganoso, e muito mais forte e solto: inabalavelmente, apesar de todos os esforços dos dispositivos de monitoramento, apesar de toda a "lógica da dominação " (MAFFESOLI, 1976), o homem permanece sendo ao mesmo tempo homo sapiens e homo demens, homo oeconomicus e homo ludens, homo faber e homo destruens. Mora em alguma parte bem profunda de cada um de nós alguma coisa que escapa à toda a vontade de unidade, algo fundamentalmente de outra ordem. Algo que os gregos, com uma fineza sem igual, identificavam sob a figura de Eros: 
Com efeito, Eros sublinha a margem de liberdade ou de resistência que o corpo social sempre consegue ter. O espirito de gatunice nunca é totalmente domesticado, e que, seja de uma maneira frontal ou de uma maneira intersticial, a liberdade, que não deve ser confundida com a ideologia da libertação, encontra neste espirito sua fonte de inspiração. Nós não repetiremos jamais o suficiente, a violência (...) permanece, em certo sentido, uma base essencial da vida comum, e mais particularmente da comunhão dos afetos (MAFFESOLI, 1991, p. 160).

Com efeito, ao querer postular uma estrutura social que tem como fundamento e critério um "processo" de repulsa aos hábitos animais ou passionais, com o controle dos afetos considerados mais violentos e selvagens (o que se chama de civilização), e considerando como patológicas ou mórbidas as formas que não se dobram a esse esquema perniciosamente imposto na intimidade dos modos e dos usos ordinários, só estaremos preparando o terreno para o licenciamento aos excessos que são próprios à categoria coercitiva. Assim, notemos, como fizeram Friedrich Nietzsche, Max Weber, Michel Foucault, Norbert Elias e ainda François Ewald, do enervamento - no sentido literal do termo, do latim, enervare, "privar de nervo, castrar, enfraquecer" - de nosso mundo social. Náo devemos nos esquecer que essa mesma civilização que nos quer mais "delicados", segundo as palavras de Nietzsche (1974, p. 74), e persistindo em uma busca desesperada por "segurança e tranquilidade da alma”, está sendo empurrada por ondas de destruição e vertigem de imagens cada vez mais negativas e corrosivas.

Então, igual a uma "homeopatização do mal", a uma expressão mesmo do vitalismo societal, ou ainda a um prazer dionisíaco que encontramos na irresistível "tentação de desacelerar a velocidade do carro diante de um acidente" como descreveu Stephen King, o superconsumo de imagens de catástrofes revela esse laço entre distração e destruição. Ela é a irrupção reencantada de Dionísio e do caos numa civilização onde a inalcançável evidência do tédio consistiu a face escondida de um cotidiano "repugnado de prosperidade, de benevolência e de segurança" (AUCLAIR, 1982, p. V), que a modernidade não parou de "limpar" (Norbert Elias), “domesticar” (Max Weber), "pasteurizar” (Friedrich Nietzsche), "vigiar" (Michel Foucault), uniformizar, trancar, normalizar, assepsiar, racionalizar em excesso. Assim, esclerosada e desencantada pelo eudemonismo ambiente, na lógica atuarial e planificadora e o no que James Graham Ballard chamou de "a tirania da felicidade" ou de "vigilância afetuosa" (2008, p. 46), a irrupção de um desastre, em definitivo, se dá como uma forma de distração na destruição e no sangue. Um pouco deste sentimento liberador que o discípulo maldito de Sigmund Freud, Victor Tausk, designou na expressão de Wandertreib ${ }^{11}$ e que se origina na busca de escapatórias cada vez mais terríveis frente a uma situação percebida como insuportável e irritante, no sentido literal do termo.

O que há de mais normal numa sociedade que não para de repulsar tanto simbolicamente quanto cientificamente a morte, na qual nós morremos em grande parte centenários e acamados, na qual o maior perigo que nos ronda é nossa sobrevivência, nossa faculdade em sempre empurrar a morte, o que há então de mais normal que as catástrofes, a luta contra os elementos, a morte no que ela tem de mais violento e gratuito? As catástrofes nos seduzem como são, quer dizer enquanto esperança mefítica de que as coisas mudem radicalmente. 
Como sublinha Christian Chelebourg nos seus livros sobre as ficçóes apocalípticas, "é ao País das Maravilhas que estas imagens nos transportam, bem mais do que num mundo dominado pelo caos" (2012, p. 135). É neste sentido que a catástrofe, ao mesmo tempo possibilidade extraordinária de palingenesia e experiência dos limites da experiência, nos interessa e finalmente nos convida a assistir ao que o romancista Jean Giono, em Un roi sans divertissement, nomeia o "teatro do rei": trata-se de uma forma de diversão diabólica - etimologicamente, é uma tautologia -com sabor áspero e selvagem, um teatro de terror e sangue, onde o tédio ordinário (Véronique Nahoum-grappe), a lógica da segurança (François Ewald), a vida planificada (Maurice de Bertaux) e a tirania da felicidade (James Graham Ballard) são as pendências e os corolários negativos.

Texto traduzido do Francês por Clélia PINTO JORON e Ricardo Ferreira FREITAS. Revisão técnica de Eduardo BIANCHI.

\section{Referências bibliográficas}

AUCLAIR, Georges. Le mana quotidien. Structures et fonctions de la chronique des faits divers, suivi de: Le double imaginaire de la modernité dans la vie quotidienne. Paris: Éditions Anthropos, 1982 (1970).

BALLARD, James Graham. La foire aux atrocités. Trad. RIVIERE, François. Paris: Tristram, 2003 (1960 e 1990).

BALLARD, James Graham. Le plus grand spectacle de télévision. Trad. GILLES, Elizabeth, In: Appareil volant à basse altitude. Paris: Denoël, 1987 (1976).

BALLARD, James Graham. Sauvagerie. Traduit par LOUIT Robert. Paris: Tristram, 2008 (1988).

BARTHES, Roland. Roland Barthes par Roland Barthes, Paris: Seuil, 1975.

BENJAMIN, Walter. L'euvre d'art à l'époque de sa reproductibilité technique. Trad. GANDILLAC, Maurice De. In: Euvres III. Paris: Gallimard, 2003 (1930).

BERGUE, Augustin. Ecoumène. Introduction à l'étude des milieux humains, Paris: Belin, 200.

BOLLNOW, Otto Friedrich. Les tonalités affectives. Essai d'anthropologie philosophique. Trad. SAVIOZ, Lydia e Raymond. Neuchâtel: La Baconnière, 1953 (1943).

CENDRARS, Blaise. La main coupée. Paris: Denoël, 1974 (1946).

CHELEBOURG, Christian. Les écofictions. Mythologies de la fin du monde. Paris: Les Impressions Nouvelles, 2012.

DEBRAY, Régis. Bonjour l'hypersphère, In: Médium, Paris, 2005/3. 2005.

DEBRAY, Régis. Cours de médiologie générale. Paris: NRF/Gallimard, 1991.

DEBRAY, Régis. Vie et mort de l'image. Une histoire du regard en Occident.

Paris: Gallimard, 1992. 
DURAND, Gilbert. Les structures anthropologiques de l'imaginaire. Introduction à l'archétypologie. Paris: Dunod, 1990 (1969).

DURAND, Gilbert. Le décor mythique de la Chartreuse de Parme. Paris: José Corti, 1983.

FLORIDI, Luciano. Philosophy and Computing. London \& New York: Routledge, 1999.

GERVERAUX, Laurent. La guerre mondiale médiatique. Paris: Nouveau Monde Editions, 2007.

JEUDY, Henri-Pierre. Le désir de catastrophe. Paris: Aubier, 1990.

KANT, Immanuel. Idée d'une histoire universelle du point de vue cosmopolitique. Paris: Aubier, 1947 (1784).

KOMATSU, Sakyo. La submersion du Japon. Trad. SHIBATA Maryse e Masumi. Paris: Albin Michel, 2000 (1973).

LA ROCCA, Fabio. Culture visuelle et visualisation du monde: L'expérience in visu. In: La postmodernité et ses multiples facettes. Perspectives et méthodes, Revista Sociétés, Paris, 2011/2, n. 112. 2011.

LORDON, Frédéric. La crise économique comme événement passionnel. Revista Critique 8/2012 (n. 783-784), 2012.

MAFFESOLI, Michel. Logique de la domination. Paris: PUF, 1976.

MAFFESOLI, Michel. L'ombre de Dionysos. Contribution à une sociologie de l'orgie. Paris: LGF-Livre de Poche, 1991 (1982).

MAFFESOLI, Michel. Du nomadisme. Vagabondages initiatiques, Paris: LGF-Livre de Poche, 1997.

McLUHAN, Marshall. Pour comprendre les médias. Les prolongements technologiques de l'homme. Trad. PARE, Jean. Paris: Mame/Seuil, 2004 (1964).

NIETZSCHE, Friedrich. Humain, trop humain II. Le voyageur et son ombre, trad. HEMERY, Jean-Claude. In: Euvres philosophiques complètes. Tome VIII, vol. 1. Paris: Gallimard, 1974 (1878).

ORTEGA Y GASSET, José. Para un Museo Romántico. Madrid: Comisaria regina del turismo y cultura artística, 1922.

POE, Edgar Allan. Le démon de la perversité et autres contes. Trad. BAUDELAIRE, Charles. Paris: Fayard - Mille et une nuits, 2010 (1845).

SILVA, Juremir Machado Da. Les technologies de l'imaginaire. Médias et culture à l'ère de la communication totale. Trad. POTTIER, Erwan. Paris: Editions de la Table Ronde, 2008 (2003).

SOMMEL, Georg. Philosophie de l'Aventure. Paris: L’Arche, 2002 (1911).

SIMMEL, Georg. Philosophie du paysage. Trad. CORNILLE, Sabine e IVERNEL, Pierre. In: La tragédie de la culture et autres essais. Paris: Payot, 2006 (1913). 
SIMON, Herbert A. Models of Man: Social and Rational. Mathematical Essays on Rational Behavior in a Social Setting. New York: Wiley, 1957.

SUSCA, Vincenzo. Joie Tragique. Les formes élémentaires de la vie électronique. Paris: CNRS Editions, 2012.

TODOROV, Tzvetan. Réflexions sur l'étrange charme de la guerre. In: Le Monde, 18 setembro 2012. Disponível em: http://www.lemonde. fr/idees/article/2012/09/18/reflexions-sur-l-etrange-charme-de-laguerre_1761862_3232.html. Acesso em: 18 de setembro de 2012.

TOFFLER, Alvin. La troisième vague. Trad. DEUTSCH, Michel, Paris: Denoël Gonthier, 1984 (1980).

VALERY, Paul. La conquête de l'ubiquité. In: CEuvres II. Paris: NRF Gallimard, Paris: 1960 (1928).

VIDAL, Bertrand. Survivre aux désastres et se préparer au pire. Revista Les cahiers psychologie politique. n. 20, jan. 2012a. Disponível em: http://lodel. irevues.inist.fr/cahierspsychologiepolitique/index.php?id=2048 Acesso em: 20 de janeiro de 2014.

VIDAL, Bertrand. Les représentations collectives de l'événement-catastrophe. Etude sociologique sur les peurs contemporaines. Tese (Doutorado em Sociologia) - Université Paul-Valéry - Montpellier III et Universidade do Minho - Braga, Montpellier, 2012b.

WEISS, Edoardo. A Comparative Study of Psycho-Analytical Ego Concepts. Revista International Journal of Psycho-Analysis. n. 38, 1957.

\section{Notas}

1. Citizenside é uma das primeiras empresas no mundo a propor soluçóes de gestão a comunidades de fotógrafos e videastas amadores, apaixonados pela atualidade.

2. BFMTV é um canal de telejornalismo, em TV aberta e também via WEB, em tempo contínuo, que tenta transmitir as notícias ao vivo.

3. Disponível em http://www.gifgif.media.mit.edu, visitado em 01/03/2016

4. Do grego Eikon, significando ao mesmo tempo imagem e presença

5. Passando também pelo naufrágio do Titanic, Auschwitz, Hiroshima e Nagazaki, Chernobyl, entre outros.

6. Em razão, de uma parte, da natureza emotiva dos hashtags ou sustenidos que lhe são associados na tuitoesfera e, de outra parte, da photogénie, da médiagénie e da mythogénie (Todorov, 2012; Vidal, 2012), que transpiram das imagens de catástrofes através da imprensa, informação televisionada e/ou internet.

7. Ver "Google Trend" (http://www.google.fr/trends/). Desenvolvido pela empresa Google Labs, é uma ferramenta que permite conhecer a frequência de entrada de uma palavra dentro do motor de pesquisa Google.

8. Na mesma perspectiva, podemos constatar que o fluxo de pesquisa pelo item "nuclear + desastre + Fukushima" precede em algumas dezenas de horas o anúncio oficial, pela Agência japonesa de segurança nuclear, sobre a fusão do reator $n^{\circ} 1$ da central de Fukushima Daiishi. 
9. Se acrescentarmos ainda a tudo isso os aplicativos por smartphone, a explosão pelos kits de sobrevivência e os abrigos antiatômicos, a multiplicação dos estágios de sobrevivência e outros campos New Age especializados na preparação TEOTWAWKI e de outras comercializaçóes do apocalipse, nós podemos, sem reserva alguma, falar de "business do fim do mundo".

10. No dia16 de janeiro de 2013, o site pornhub.com publicou o quadro apresentando os 11 dias do ano de 2012 durante os quais os utilizadores eram em menor número à estarem conectados, e assim os dias onde a pornografia era menos solicitada no Internet. É interessante notar que esses dias estão ligados as festas nacionais norteamericanas e as festas religiosas cristâs. É instrutivo observar que entre essas datas figura o 20 de outubro de 2012 em sétima posição, dia que corresponde ao furacão Sandy. Se os jornalistas tentaram explicar esta queda de frequentação por causa dos cortes de eletricidade devidos ao furacão, como relata o site complex.com, esta explicação fica totalmente inapropriada. Assim, na costa leste dos Estados Unidos, onde o corte de eletricidade foram os mais importantes, uma grande parte da população preparou ao furacão «baixando com antecedência vídeos pornográficos ", o que aumentou a frequentação dos sites pornô nestas regioóes. Disponível em: http://www.complex.com/city-guide/2012/11/statistics-reveal-what-numerouspeople-on-the-east-coast-did-prior-to-hurricane-sandy Acesso em: 17 de agosto de 2013.

11. Aliás, se nos referimos à ferramenta Google Trend, observamos que existe uma espécie de "lei do pornô " relativa ao consumo cotidiano: quando efetuamos uma pesquisa do item "porn + vídeo", a curva é sinusoidal ao nível semanal, com uma evoluçáo constante das buscas $(+1 \mathrm{pt})$ da segunda à quinta-feira, um crescimento de mais de 3 pts na sexta feira e de 1 pt no sábado, e uma queda de 18 pts no domingo. Entre 2004 a 2013, os números e as frequentaçóes são os mesmos, sabendo que cotidianamente as buscas relativas à pornografia numérica corresponde em média há mais de 68 milhôes de buscas, representando mais de $25 \%$ do tráfico no World Wide Web. Contudo, a sexta-feira 11 de março de 2011, dia do sismo e do tsunami, houve uma exceção: o fluxo de busca do item "porn + vídeo " caiu mais de 4 pts, enquanto que para o item «tsunami + vídeo » houve um aumento de mais 100 pts, o que representa para Google Trend o pique máximo de popularidade.

12. Ver Contributions à la psychologie du déserteur, 1916. Trata-se de uma pulsão de vagabundagem, que caracteriza também as sociedades pós-modernas, segundo as análises de Michel Maffesoli no seu livro Du nomadisme (1997). 